\title{
REMEDIOS CASEROS: MEXICAN AMERICAN HOME REMEDIES AND COMMUNITY HEALTH PROBLEMS
}

\author{
ROBERT T. TROTTER II \\ Department of Behavioral Sciences, Pan American University, Edinburg, TX 78539, U.S.A
}

\begin{abstract}
A sample of 1235 case examples of remedios caseros (home remedies) was analyzed to determine the morbidity patterns for "home treated" ailments in Mexican American communities in South Texas. A group of seventy most commonly encountered ailments was discovered, as described in the paper. An analysis was made of the variations within the morbidity patterns of these ailments in relation to the age and sex of the informant. Parallels are drawn between the research findings and the results of conventional morbidity research efforts.
\end{abstract}

Investigations of the patterns of community health problems in the United States are of relatively recent advent* and are normally pursued within the context of a demographic analysis of morbidity. While morbidity has been defined by Tomlinson $[1, \mathrm{p} .138]$ as "the study of illness", the more commonly accepted definition is that of the United States National Health Interview Survey, which defines morbidity as:

basically a departure from a state of physical or mental well-being, resulting from disease or injury, of which the individual afflicted is aware. Awareness connotes a degree of measurable impact on the individual or his family in terms of the restrictions and disabilities caused by the morbidity $[2, \mathrm{p} .42]$.

Most morbidity research divides illness into chronic or acute states and attempts to measure either the incidence, $\dagger$ prevalence $\ddagger$ or both of biological and of psychological ailments. The protocols for the National Health Interview Survey state:

A condition is considered to be chronic if (1) it is described in terms of one of the chronic diseases on the "Checklist of Chronic Conditions" or in terms of one of the impairments on the "Checklist for Impairments"... or (2) the condition is described by the respondents as having been first noticed more than 3 months before the week of the interview.

An acute condition is defined as a condition which has lasted less than 3 months and which has involved either medical attention or restricted activity [2, p. 45].

The most common foci of morbidity research are either household surveys or institutionally based studies that attempt to look at morbidity in relation to hospitals, doctors' offices, clinics, etc. These research efforts normally attempt to measure the occurrence of disease states that are recognized by the medical system, using instruments developed for that

* As an example, national attention to morbidity data collection did not occur to any significant extent until the advent of the National Health Interview Survey (NHS) in 1956. Even now, formal demographic texts often pay scant attention to the subject.

† The incidence rate is equal to the number of new cases during a specified period of time per unit of the midpoint population $[5$, p. 236$]$.

$\ddagger$ The prevalence rate is equal to the number of persons diagnosed as having a condition on any given day per uni of the total population $[5$, p. 236]. purpose [see 2, 3]. Unfortunately, the weaknesses of these studies are relatively numerous. Central to these weaknesses is the condition that morbidity is far more difficult to identify than the other major demographic measure of health, mortality. Death is a reasonably clear-cut event, and its cause can usually be traced to one or more of the entities listed in the International Classification of Diseases. On the other hand, as Peterson [5] clearly demonstrates, the recognition of an illness or ailment is an event that is based on the subjective interpretation of symptoms by patients or their families. To overcome this problem, some morbidity studies have turned away from clinical measures of health status and have developed a number of instruments designed to categorize and quantify the informant's life condition, including such nebulous states of well-being as happiness [see 6-7]. Unfortunately, as Mechanic points out, the indirect measure of "health status is so involved with subjective perceptions, social expectations, role demands, and value judgments... (that these measurements often become)... only poor approximations of the concepts the investigators wish to study" $[9$, p. 183] And as Peterson [5, p. 239] indicates, a comparison of morbidity patterns across cultural boundaries becomes particularly perilous. This is partially due to the condition that the rank ordering of the importance of diseases to a community is normally based on quantitative evaluations of the reported incidence, or prevalence, of previously defined illnesses. This is a practice which is generally acceptable for a dominant cultural group, such as Anglo Americans in the United States, since the categories of illnesses being measured are relatively well agreed upon by both the informants and the evaluators. However, this agreement is not necessarily pertinent for ethnic groups or members of other cultures who recognize and behaviorally react to disease entities not recognized by the dominant group, and who may fail to recognize diseases that are a part of the medical model $[5, \mathrm{pp}$. 235-244].

This paper presents an alternative method for exploring community morbidity patterns for groups where more conventional approaches either have not been undertaken, or cannot be conducted at present. The method utilizes an anthropological approach for the derivation of a typology of ailments, combined with quantification to allow the rank ordering of ail- 
ments in relation to their "prominence"* in the community. Developing a community based classification of ailments avoids the cultural bias of the methods previously mentioned, however, it produces its own weakness in that it does not generate incidence and prevalence rates comparable to other studies. This weakness can be considered minor, in light of the fact that the illness typology produced by this method can subsequently be used to generate surveys of morbidity, using more conventional methodologies, when time and financial resources (or interest) permit.

\section{RESEARCH AREA AND POPULATION}

The data for this paper were collected in the Lower Rio Grande Valley of Texas, commonly called the Valley by local residents. The Valley is composed of four Texas counties (Starr, Hidalgo, Willacy and Cameron) adjacent to the United States-Mexico border at the mouth of the Rio Grande River. It contains numerous small and medium-sized towns, the largest of which are Brownsville, Harlingen, and McAllen. The estimated half-million people in the Valley live in a nearly continuous "population strip" following the river and the railroad up and down the Valley in an approximately east-west direction.

Agriculture is the primary Valley industry, although assembly plants, maquiladoras, and U.S.Mexico "sister" plants are being introduced into the local economy. This condition, along with the demographic spread of the population, has produced an area that is neither rural nor urban, but some inextricable combination of the two.

With the exception of the immediately adjacent border towns of Reynosa and Matamoros (Tamaulipas) Mexico, the Valley is somewhat isolated. The nearest towns of any significant size are Corpus Christi and San Antonio, 130 and 250 miles away respectively. This relative isolation, along with the extreme ease of movement between the United States and Mexico causes the Mexican border towns to have both a strong cultural, as well as economic impact on the Valley. Part of the impact comes from the nearly one million people on the Mexican side of the river who account for between 40 and $60 \%$ of the retail trade in the Valley, while they also provide a large labor pool that reduces upward wage pressures and makes both seasonal and permanent underemployment a chronic problem for Valley residents. The result is that the Valley contains the two poorest Standard Metropolitan Statistical Areas surveyed in the 1970 Census of Population. At that time the per capita income in Hidalgo County was $\$ 1777$ per annum, with over hall of the population falling below federal poverty guidelines. There is no indication that the 1980 Census will significantly revise the economic profile of the area.

The demographic characteristics of the Valley are

* Prominence is defined as the likelihood that a particular illness will be presented in a case example of the home treatment of health problems, within the context of a nondirective interview that seeks to collect such treatments.

† The form was developed by Dr Mark Glazer, Department of Behavioral Sciences, Pan American University. The author would like to thank Dr Glazer for allowing him the use of the form for data collection purposes. as interesting as its economic characteristics are grim. The population is young, over half being under 25 years of age, by current estimates. Approximately $80 \%$ of the residents are Spanish surnamed and/or of Mexican descent, another approximately $20 \%$ of the residents are Anglo American, and less than one half of $1 \%$ are Black. The area is distinctly bilingual and bicultural. The population dynamics of the Valley are further complicated by the presence of approximately 130-150 thousand migrant farmworkers who make the Valley their home, but who spend from 3-6 months out of the area participating in the migrant stream northward. Finally, an estimated 200 thousand winter residents, most of whom are retired, make the Valley their home between October and March. All of these characteristics combine to make the Valley an area of key interest for social research in the United States.

\section{METHODOLOGY}

The methodology utilized in collecting the data for this report combines the strength of an open ended case study approach for generating a community based typology of ailments (as opposed to testing for the presence of a priori categories thought to be important by the researcher) with the potential for quantification. Each case that was collected within a common format by being recorded on a data collection form. $\dagger$ The data recorded on the form includes the common name (either English, Spanish, or other languages) of the remedio casero (home remedy) and its English translation, if available; the scientific name of the remedy, if available; the type of illness or illnesses treated by the remedy; a description of the method of preparation of the remedio; a case description of a known use of the remedy; basic sociocultural data about the informant (name, age, sex, address, where born, languages spoken); and identifying information about the interviewer/collector (name, address, etc.).

A sample of case examples was drawn from the over 2000 cases currently available in the ethnopharmacological archive at Pan American University. The archive cases were collected from members of three different U.S. ethnic groups and a large number of foreign nationals, however, only those cases coded as being presented by a Mexican American informant were retained for analysis for this paper.

The sample was drawn in a way that not only retained cases presented by Mexican American informants, but also assured that all of the cases presented by each informant would be contained in the sample. This was done to assure that the data could provide a preliminary estimate of the breadth of knowledge of various informants. The number of case examples presented by informants ranged from 1 to 29 . However, this number should not be taken as the upper limit of knowledge of remedios caseros in the community. An upper limit of 25 cases was imposed on collectors as being the maximum number of cases that could be collected from a single informant without unduly taxing the informant's patients and goodwill. Thus, even though most of the informants presented far less than 25 cases (mean $=3.3$; median $=2$; mode $=1$ ), there are individuals in the Valley communities who specialize in herbal knowledge called 
yerberos, who know literally hundreds of remedies [see 10].

The sample contains 1235 cases collected from 378 informants ranging in age from 15 to 86 (mean $=50.5 ;$ median $=50 ;$ mode $=50)$. All of the informants in the sample identified themselves as Mexican American; $58.6 \%$ of the cases were provided by individuals born in the United States, while $41.4 \%$ of the cases were provided by individuals born in Mexico. A later report will measure whether or not there are significant differences in the remedios and ailments reported by these two groups. Women predominate in the sample; $85.4 \%$ of the cases (1050), where sex is identified, were collected from women, while $14.6 \%(179)$ were collected from males $(6$ had no sex identifier). This is generally representative of the study population, in that ethnographic data collected in the Valley indicates that women are normally the primary informants about remedios caseros. Therefore, the sample can be considered representative of the general knowledge about remedios caseros in the area.

The sample should probably be considered a convenience sample, since no effort was made to assure that the data collected for the ethnopharmacological archive would be amassed in a way that made it representative of any specific geographical or sociocultural characteristics of the Valley. Nevertheless, an inspection of the data indicates that it is consistent with the results of ethnographic research conducted by the author and others, and that the informants cover the demographics of the Valley area without

* The 25 most common remedios caseros are: manzanilla (cammomile) Matricaria chamomilla L.; savile (aloe vera) Aloe barbadensis Mill.; ruda (rue) Ruta graveolens L.; yerba aniz (anise) Pimpinella anisum L.; yerba buena (mint) Mentha spicata $\mathrm{L}$., estafiate (worm wood) Artemisia mexicana Willd.; hojas de naranjo (orange leaves) Citrus aurantium L., albacar (sweet basil) Ocimum basilicum L.; oregano (oregano) Monarda methaefolia Graham; ajo (garlic) Allium sativum L.; pelos de elote (corn silks) Zea mays L.; canela (cinnamon) Pulchea orodata (L) Cass; romero (rosemary) Rosmarinus officinalis L.; borraja (borrage) Borajo officinalis L.; cenizo (purple sage) Leucophyllum texanum Benth.; nopal (prickly pear cactus) Opuntia sp.; Rosa de Castillo (rose) Rosa centifolia sp.; salvia (sage) Salvia leucantha Cav.; hojas de mesquite (mesquite leaves) Prosopis glandulosa Torr.; marijuana (marijuana) Cannabis sativa L.; nogal (pecan) Carya illonoensis Koch; comino (cumin) Arracacio atropurpurea Benth. et. Hook; golondrina (swallow-wort) Euphorbia prostrata Ait.; sacate de limon (lemon grass) unidentified local plant; el azajar (orange blossoms) Citrus aurantium $\mathrm{L}$.

†Table 1 was limited to those ailments which were repeated in the sample at least four times. Including ailments that represented approximately $0.2 \%$ of the cases (the other multiple example cases) would have increased the core group by the addition of 35 ailments, but would only have increased the cumulative percentage of cases by $7.0 \%$ too large an increase for too small an addition to warrant their inclusion. The final 93 ailments were single example cases from the sample. Since they were not repeated, they were considered to be inappropriate for inclusion in the core group. In fact, the core group could easily be restricted to the top forty or fifty most commonly encountered ailments and still represent the bulk of the key morbidity problems found within the Mexican American communities of South Texas. unduly clustering in any one area, age group, or social group. Therefore, the results are reasonably representative of the ethnopharmacological knowledge and practices of the region.

\section{THE DATA}

One assumption was made about the case data that is central to the results of this paper. It was assumed that when people were asked in a nondirective manner to recall remedios caseros, the ones they recounted would be either the ones they most commonly used or the ones that treated ailments that had been significant events in either their own lives or the life of someone important to them. In either situation, the most frequently repeated case examples are assumed to be the ones that represent a combination of common and key ailments in the community. Those less frequently presented are assumed to represent unusual or less frequently encountered community ailments. A total of 510 remedios caseros (both botanical and non-botanical items) treating 198 discrete illnesses were discovered in the sample. Within this field, there was clearly a core group of remedios that constituted the bulk of those presented in the sample cases. The 25 most frequently encountered remedios $(4.9 \%$ of all remedios discovered) constitute $40.9 \%$ of the total cases in the sample.* Since each remedio is linked to one or more ailments it is obvious that there is also a core group of ailments which informants feel are amenable to home treatment. Although, it might be more accurate to state that each ailment is linked to one or more remedio, since new remedios were encountered and coded throughout the coding process at approximately the same frequency, while the ailments began to repeat very rapidly and almost no new ailments were added to the informant's ailment typology from the point when about half of the total sample was coded. The core group of ailments is presented in Table 1.

The sample produced a core group of 70 most frequently encountered ailments that are treated by remedios caseros. These remedies (representing 35.9\% of the total 198 ailments) constitute $84.0 \%$ of all of the cases. $\dagger$

This group of ailments is assumed to be an ethnotypology of health problems within Mexican American communities, especially those ailments that informants feel can or should be given home treatment as opposed to medical attention. The labels of the ailments (or conditions) were taken directly from the collection form, without modification. Those ailments that could be translated (or had been by the informants) are rendered in the table in English. Care was taken to assure that the exact English equivalent of a Spanish term was used and where there is no English equivalent, the Spanish was retained. In most cases, the informants provided the translation, but where they did not do so, matches were sought with similar cases, or other informants in the community were utilized to provide the translations. Some of the original list of ailments produced by this method were combined in the table (e.g. upset stomach and indigestion; or body aches and aches and pains) into a single ailment category, since informants tended to fail to be able to differentiate amongst the labels and used them 
Table 1. Most common ailments treated by remedios caseros

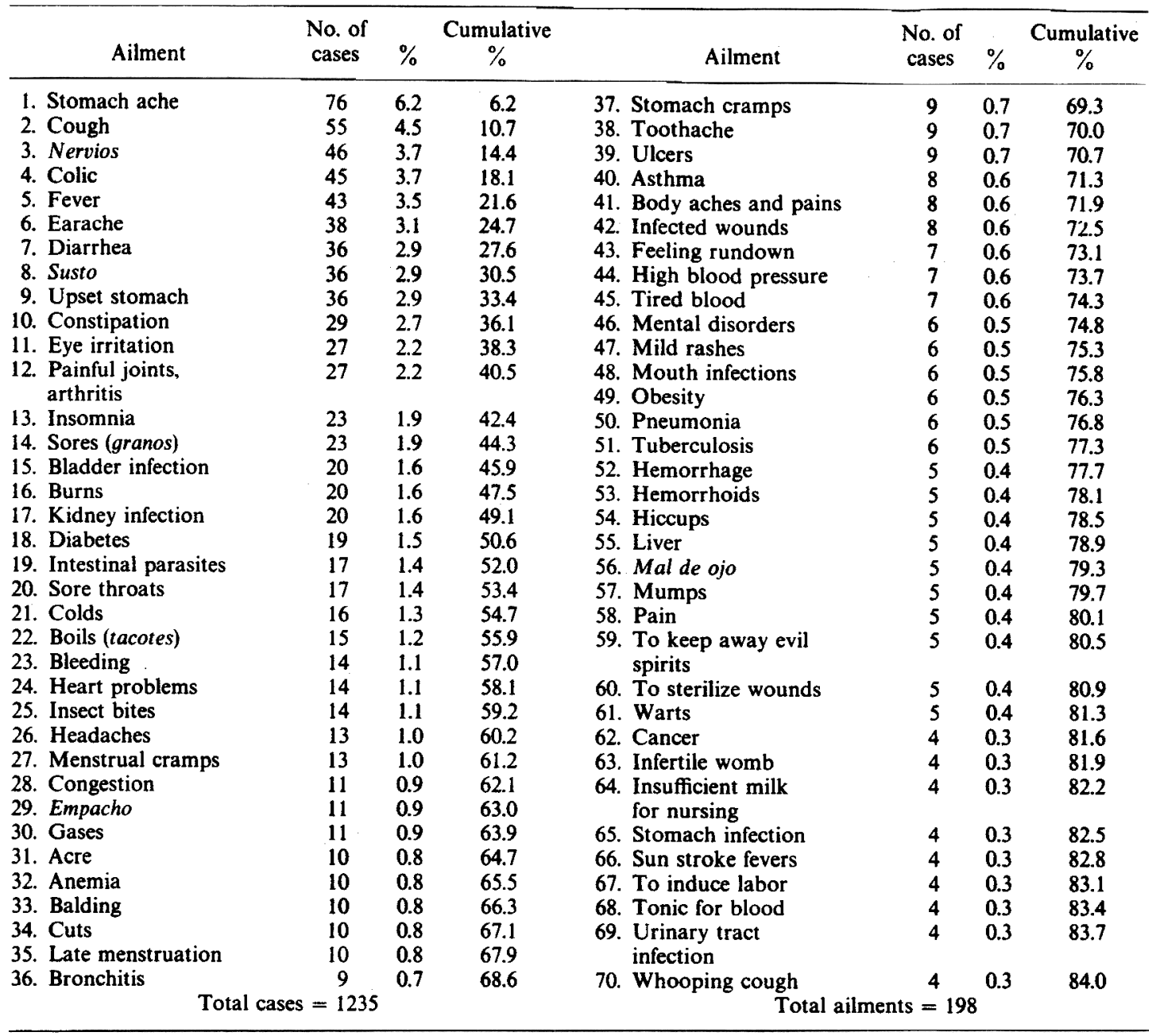

interchangeably. The resulting list is assumed to contain only conditions that are considered by the informants to be mutually exclusive categories. If there is any error in the categories, it is probably in the direction of lumping together categories that should have remained separate rather than from retaining categories that duplicated or overlapped one another.

\section{MORBIDITY PATTERNS}

The core ailments can be assembled into groups of related illnesses which are useful for an analysis of some of the trends in morbidity derived from the data. Although these groupings do not represent a folk taxonomy of ailments, several interesting attributes of the morbidity patterns in Mexican American communities are apparent from an inspection of Table 1. The first is the inclusion of ailments that have no English equivalents and are basically of a magical or supernatural nature. These ailments are susto, empacho, keeping evil spirits away, mal de ojo, and caida de mollera (one case, not listed in the core group). They are the so-called Mexican American folk illnesses that have received such prominent attention in the anthropological literature, since the folk medical system makes this basic distinction between natural and magical ailments [see 11-16]. The presence of these ailments, in and of themselves, guarantees that the morbidity patterns of Mexican Americans are different from those of Anglo Americans. However, caution should be maintained to avoid overemphasizing the prominence and importance of these ailments within the ethnomedicine of Mexican Americans. To ignore them because they do not fit the medical model would be a serious mistake, one which would distort the actual morbidity patterns in Mexican American communities, since these illnesses are "a departure from a state of... well-being of which the individual afflicted is aware" [2]. At the same time, these ailments represent only $2.5 \%$ of the total group of ailments in the sample and constitute only $4.7 \%$ of the total sample of cases. So the underemphasis of the treatment of other ailments, as has been done in the past, is equally inappropriate and produces an even more serious distortion of community health patterns in places such as the Lower Rio Grande Valley.

In addition to the folk illnesses, there are several other groups of ailments that provide insight into the home treatment of health care problems in Mexican American communities. These include digestive sys- 
tem problems, upper respiratory ailments, infectious and parasitic diseases, injuries and environmentally produced ailments, other acute conditions, mental problems, and chronic ailments. These categories correspond, at least partially, with the groupings of illness most frequently presented in morbidity tables and articles. Since some of the ailments listed in Table 1 could potentially be placed in more than one of these categories, the list of ailments assigned to each is presented within the context of the discussion of that grouping.

The digestive system problems listed in the core ailment group include stomach aches, colic, diarrhea, upset stomach, constipation, gases, stomach cramps and ulcers. These ailments account for $20.7 \%$ of the total cases in the sample, which makes them the single most prominent group of closely related ailments in the community. This finding is consistent with other morbidity studies, since, as Cole $[17$, p. 36$]$ indicates, problems with the digestive system are reported much more frequently amongst low income families than amongst families of moderate or high income.

The core group of upper respiratory infections includes coughs, sore throats, colds, congestion, bronchitis, pneumonia, and whooping cough. These ailments account for a total of $9.6 \%$ of the total cases in the sample. In most morbidity studies, upper respiratory infections constitute the largest single group of ailments $[17, \mathrm{p} .34]$ with the common cold being the principle contributor to incidence rates. Colds rank 21 st on the core group list, however, when the category "colds" is combined with two cold symptoms (coughs and congestion) the group cases equal $6.7 \%$ of the total sample and would rank first on the core list.

Infectious and parasitic diseases listed in the core ailment group include intestinal parasites, tuberculosis, and mumps, which account for $2.3 \%$ of the sample of cases. Public heath morbidity reports from the Lower Rio Grande Valley all indicate that the rates for nearly all infectious diseases are significantly higher than elsewhere in the United States. Two factors, the poverty of the area and the proximity and ease of access to Mexico, are blamed for this condition. Yet, this condition does not appear to be reflected in the core ailment group. One explanation for this is that the majority of infectious diseases are now viewed as being best treated by medical intervention, and they are, therefore, no longer a part of the home treatment or ethnopharmacological system.

The category injuries and environmentally produced ailments includes eye irritation, sores, burns, bleeding, insect bites, cuts, wounds ( 2 categories), mild rashes, and sun stroke. These ailments represent $8.5 \%$ of the cases analyzed for this paper. These ailments are primarily first aid problems and are not easily comparable to the accident category that is presented in most morbidity studies [17, p. 35].

The final grouping of acute illnesses, "other acute illnesses", includes fevers, earaches, bladder infections, kidney infections, boils, headaches, menstrual cramps, acne, anemia, late menstruation, toothaches, aches and pains, feeling rundown, tired blood, mouth infections, hemorrhage, hemorrhoids, hiccups, liver problems, pain, warts, infertile womb, insufficient milk, stomach infection, inducing labor and urinary tract infection. The sum of all the cases in this group is equal to $22.3 \%$ of the total sample of cases. The ailments in this group are very similar to the group of "other acute ailments" reported for the United States as a whole. Cole states the following:

Among the category of "other acute ailments" for females, about one-fifth were reported as genitourinary problems and one-eighth as deliveries and disorders of pregnancy and puerperium. Among males, over one-fourth of this residual category was reported as diseases of the ear, onesixth as diseases of the skin, and about one-tenth as headaches. These conditions were also prominent among females $[17$, p. 35$]$.

An inspection of the list of ailments in this category shows that these are also prominent ailments treated by home remedies. The comparison of ailments by sex is presented below.

Chronic ailments are normally separated out from acute ones for special emphasis in morbidity studies, and have even formed the topic of interest for specific studies. The chronic ailments found in the core group are arthritis, diabetes, heart problems, balding, asthma, high blood pressure, obesity, and cancer, which constitute $5.4 \%$ of all of the cases analyzed. Approximately one-half of the civilian non-institutional population of the United States commonly reports having more chronic conditions $[17$, p. 38], however, only $1.2 \%$ of the females and $3.0 \%$ of the males were considered disabled to the extent they could not work or do whatever they were doing prior to the disability $[17$, p. 40$]$. Listed in the conditions reported nationwide as most commonly restricting activity were arthritis, visual impairments, hearing impairments, high blood pressure, heart conditions, digestive conditions, and orthopedic impairments [17, pp. 40-42]. Obesity is generally not labeled as an illness in medically based surveys, while asthma and diabetes are not amongst the prominent problems listed by Cole for the United States as a whole. This makes a comparison of the ethnographic and demographic data difficult, however, it is interesting to note that both studies listed four ailments as prominent problems: arthritis, digestive conditions, heart problems, and high blood pressure. Equally germane is the growing concern in the Valley over the evidence that there is a higher incidence of diabetes amongst Mexican Americans than the country as a whole $[18, \mathrm{p}$. 44]. Cancer was placed in the chronic illness category by the author, since its duration is often more than three months, but a similar treatment was not found in Cole [17], Peterson [5], Tomlinson [19] or Mechanic [9]. The other illness in this category, balding, represents a community health concern that would not be considered a high priority condition by the medical establishment, but is of concern within the community. It is discussed in more detail below.

The final category of illnesses derived from grouping the core ailments is the category of "mental problems". These include the categories nervios, insomnia, and mental disorders. Nervios is a broad condition that includes anxiety, irritability, and insomnia but has no exact English equivalent, either as a folk illness or as a medical condition. The category "mental disorders" includes depression, sadness, the relief of general mental disorders, and the restoration of sanity. The broadness and inexactness of definition of these 
Table 2. Sex specific comparisons of frequencies of ailment case examples

\begin{tabular}{|c|c|c|c|c|c|c|c|}
\hline \multicolumn{4}{|c|}{ Females } & \multicolumn{4}{|c|}{ Males } \\
\hline Ailment & $\begin{array}{l}\text { No. of } \\
\text { cases }\end{array}$ & & $\begin{array}{c}\text { Cumulative } \\
\%\end{array}$ & Ailment & $\begin{array}{l}\text { No. of } \\
\text { cases }\end{array}$ & $\%$ & $\begin{array}{c}\text { Cumulative } \\
\%\end{array}$ \\
\hline 1. Stomach ache & 67 & 6.4 & 6.4 & 1. Arthritis & 9 & 5.0 & 5.0 \\
\hline 2. Cough & 50 & 4.8 & 11.2 & 2. Fever & 9 & 5.0 & 10.0 \\
\hline 3. Colic & 44 & 4.2 & 15.4 & 3. Stomach ache & 9 & 5.0 & 15.0 \\
\hline 4. Nervios & 41 & 3.9 & 19.3 & 4. Upset stomach & 9 & 5.0 & 20.0 \\
\hline 5. Earache & 37 & 3.5 & 22.8 & 5. Constipation & 8 & 4.5 & 24.5 \\
\hline 6. Susto & 35 & 3.3 & 26.1 & 6. Diarrhea & 7 & 3.9 & 28.4 \\
\hline 7. Fever & 34 & 3.2 & 29.3 & 7. Sore throats & 6 & 3.4 & 31.8 \\
\hline 8. Diarrhea & 29 & 2.8 & 32.1 & 8. Intestinal parasites & 5 & 2.8 & 34.6 \\
\hline 9. Eye irritation & 23 & 2.2 & 34.3 & 9. Nervios & 5 & 2.8 & 37.4 \\
\hline 10. Upset stomach & 23 & 2.2 & 36.5 & 10. Boils & 4 & 2.2 & 39.6 \\
\hline 11. Constipation & 21 & 2.0 & 38.5 & 11. Cough & 4 & 2.2 & 41.8 \\
\hline 12. Insomnia & 20 & 1.9 & 40.3 & 12. Eye irritation & 4 & 2.2 & 44.0 \\
\hline 13. Sores & 20 & 1.9 & 42.3 & 13. Insect bites & 4 & 2.2 & 46.2 \\
\hline 14. Arthritis & 18 & 1.7 & 44.0 & 14. Kidney infection & 4 & 2.2 & 48.4 \\
\hline 15. Burns & 18 & 1.7 & 45.7 & 15. Backache & 3 & 1.7 & 50.1 \\
\hline 16. Bladder infection & 17 & 1.6 & 47.3 & 16. Bladder infection & 3 & 1.7 & 51.8 \\
\hline 17. Diabetes & 17 & 1.6 & 48.9 & 17. Feeling rundown & 3 & 1.7 & 53.5 \\
\hline 18. Kidney infection & 16 & 1.5 & 50.4 & 18. High blood pressure & 3 & 1.7 & 55.2 \\
\hline 19. Colds & 14 & 1.3 & 51.7 & 19. Heart problems & 3 & 1.7 & 56.9 \\
\hline 20. Headaches & 13 & 1.2 & 52.9 & 20. Insomnia & 3 & 1.7 & 58.6 \\
\hline 21. Intestinal parasites & 12 & 1.1 & 54.0 & 21. Sores & 3 & 1.7 & 60.3 \\
\hline \multicolumn{4}{|c|}{ Total cases, female informants $=1050$} & \multicolumn{4}{|c|}{ Total cases, male informants $=179$} \\
\hline
\end{tabular}

ailments makes a comparison of these problems with clinical mental health categories impossible until enough further research has been done to more precisely define them and their treatment within an ethnographic context. This category represents $6.1 \%$ of the total sample of cases.

\section{AGE AND SEX COMPARISONS}

Most morbidity studies include a comparative analysis of morbidity patterns by sex and by age ranked groups within the gender categories. The data collected for this paper were sufficient to allow a partial analysis of the sex and age related differences in home treated morbidity problems in the Valley. However, a certain amount of caution should be maintained in applying this data elsewhere, due to the relatively small number of case examples collected from male informants. Thus, this must be considered an exploratory, rather than a final analysis of sex and age specific morbidity problems.

Table 2 presents the 21 most commonly recorded ailments for all males and for all females, along with the frequency of reporting of each ailment within the respective group, but not for the total sample of cases.

Even a casual inspection of the rankings for the two sexes indicates a considerable divergence between the two groups, which is confirmed by computing a chisquared statistic for the table that indicates that there is less than one chance in a thousand that the differences between the group was produced by chance alone $\left(\chi^{2}=621.3,27 \mathrm{df}, P<0.001\right)$. Thus, there are age specific differences in the reporting of remedios caseros by males and females which are probably linked to differences in their morbidity patterns (see Tomlinson [19], Cole [17], Mechanic [9] and Peterson [5] for discussions of the causes for these differences).
There were 10 ailments from Table 1 , the core ailment group, that were collected only from female informants. These included colic (44 cases), headaches (13 cases), balding (10 cases), tired blood (6 cases), hemorrhoids ( 5 cases), keeping away evil spirits (5 cases), mumps ( 5 cases), infertile womb (4 cases), urinary tract infection (4 cases), and whooping cough (4 cases). Other multiple example ailments presented by females, but not by males, include dolor del aire, chills, babies' diarrhea, bad luck, deformaties, bed wetting, nose bleeds, sprained joints, ringworms, dandruff, paño (dark spots on the skin), dry irritated skin, measles, loss of appetite, to gain weight, anxiety, face problems (spots, rough skin), help close navel on newborns, and to clean the uterus. There were seven conditions presented by males alone (restoring eyesight, clean out stomach, poison oak, keep teeth and gums healthy, stay awake, abscesses, and intestinal flu), but since they are all single example cases, it is impossible to assess their importance until the sample of cases from male informants is increased significantly.

Some patterns are suggested by the above data. A number of the ailments collected solely from women are childhood diseases, such as colic, mumps, and whooping cough, which suggests a much greater role of females in the treatment of these illnesses than for males. Others are "female problems," such as infertile womb (along with morning sickness, vaginal douches, yeast infections, which were not in the core group). The fact that no males reported keeping away evil spirits as a problem may be due to the greater role women in the community play in participating in religious activities. However, as yet there is no explanation, and not even a decent speculation, as to why only women reported balding as a community health problem, especially given that balding is in the top half of the core ailment group. 
Table 3. Age and sex specific comparisons of frequencies of ailment case examples, ages: 17-44

\begin{tabular}{|c|c|c|c|c|c|c|c|}
\hline \multicolumn{4}{|c|}{ Females } & \multicolumn{4}{|c|}{ Males } \\
\hline Ailment & $\begin{array}{l}\text { No. of } \\
\text { cases }\end{array}$ & $\%$ & $\begin{array}{c}\text { Cumulative } \\
\%\end{array}$ & Ailment & $\begin{array}{l}\text { No. of } \\
\text { cases }\end{array}$ & $\%$ & $\begin{array}{c}\text { Cumulative } \\
\%\end{array}$ \\
\hline 1. Stomach ache & 21 & 6.8 & 6.8 & 1. Upset stomache & 6 & 8.5 & 8.5 \\
\hline 2. Nervios & 15 & 4.8 & 11.6 & 2. Constipation & 5 & 7.1 & 15.6 \\
\hline 3. Colic & 12 & 3.9 & 15.5 & 3. Intestinal parasites & 5 & 7.1 & 22.7 \\
\hline 4. Cough & 12 & 3.9 & 19.4 & 4. Painful joints & 4 & 5.7 & 28.4 \\
\hline 5. Diarrhea & 12 & 3.9 & 23.3 & 5. Diarrhea & 3 & 4.3 & 32.7 \\
\hline 6. Earache & 11 & 3.5 & 26.8 & 6. Fever & 3 & 4.3 & 37.0 \\
\hline 7. Constipation & 10 & 3.2 & 30.0 & 7. Sore throats & 3 & 4.3 & 41.3 \\
\hline 8. Susto & 10 & 3.2 & 33.2 & 8. Stomach ache & 3 & 4.3 & 45.6 \\
\hline 9. Fever & 8 & 2.6 & 35.8 & 9. Boils (tacotes) & 2 & 2.9 & 48.5 \\
\hline 10. Upset stomach & 8 & 2.6 & 38.4 & 10. Colds & 2 & 2.9 & 51.4 \\
\hline 11. Eye irritation & 7 & 2.3 & 40.7 & 11. Gas & 2 & 2.9 & 54.3 \\
\hline 12. Kidney infection & 7 & 2.3 & 43.0 & 12. Nervios & 2 & 2.9 & 57.2 \\
\hline 13. Sores (granos) & 7 & 2.3 & 45.3 & & & & \\
\hline \multicolumn{4}{|c|}{ Total $=311$} & \multicolumn{4}{|c|}{ Total $=70$} \\
\hline
\end{tabular}

The comparisons presented in Table 2 are further refined in Tables 3 and 4 , which present the age specific comparisons of the most commonly reported ailments of males and females from the sample cases.

Age specific comparisons are commonly reported for the age ranks of $0-6,7-16,17-44$ and 45 and over $[17$, p. 34]. However, there were only eight cases in the sample that were collected from males under the age of seventeen years old, so only the two comparisons of age ranks in Table 3 and Table 4 are presented. The reason for the difference in the size of the lists of ailments is that the lists were restricted to multiple example ailments reported for the males, and the length of the female rankings was conformed to that of the male list of multiple examples.

Dividing the data into these groupings allows a three-way comparison of the listing of the ailments: between males and females in each of the two age ranks, and between the same sex informants in the two different age ranks. The differences between the ailments presented by the males and females within each rank is far greater than it would have been if produced by chance alone $\left(\chi^{2}=181.2, \quad 18 \mathrm{df}\right.$, $P<0.001$ for ages 17-44; and $\chi^{2}=254.7,33 \mathrm{df}$, $P<0.001$ for ages $45+$ ). This indicates that sex roles, occupation, cultural values and other socio-cultural

Table 4. Age and sex specific comparisons of frequencies of ailment case examples, age: $45+$

\begin{tabular}{|c|c|c|c|c|c|c|c|}
\hline \multicolumn{4}{|c|}{ Females } & \multicolumn{4}{|c|}{ Males } \\
\hline Ailment & $\begin{array}{l}\text { No. of } \\
\text { cases }\end{array}$ & $\%$ & $\underset{\%}{\text { Cumulative }}$ & Ailment & $\begin{array}{l}\text { No. of } \\
\text { cases }\end{array}$ & $\%$ & $\underset{\%}{\text { Cumulative }}$ \\
\hline 1. Stomach ache & 41 & 6.0 & 6.0 & 1. Fever & 6 & 5.9 & 5.9 \\
\hline 2. Cough & 36 & 5.3 & 11.3 & 2. Stomach ache & 5 & 5.0 & 10.9 \\
\hline 3. Colic & 32 & 4.7 & 16.0 & 3. Diarrhea & 4 & 4.0 & 14.9 \\
\hline 4. Upset stomach & 26 & 3.8 & 19.8 & 4. Kidney infection & 4 & 4.0 & 18.9 \\
\hline 5. Nervios & 25 & 3.7 & 23.5 & 5. Painful joints & 4 & 4.0 & 22.9 \\
\hline 6. Susto & 25 & 3.7 & 27.2 & 6. Backache & 3 & 3.0 & 25.9 \\
\hline 7. Earache & 21 & 3.9 & 30.3 & 7. Bladder infection & 3 & 3.0 & 28.9 \\
\hline 8. Fever & 20 & 2.9 & 33.2 & 8. Constipation & 3 & 3.0 & 31.9 \\
\hline 9. Diarrhea & 16 & 2.4 & 35.6 & 9. Cough & 3 & 3.0 & 34.9 \\
\hline 10. Eye irritation & 14 & 2.9 & 37.7 & 10. Eye irritation & 3 & 3.0 & 37.9 \\
\hline 11. Insomnia & 14 & 2.9 & 39.8 & 11. Feeling rundown & 3 & 3.0 & 40.9 \\
\hline 12. Painful joints & 14 & 2.1 & 41.9 & 12. Insect bites & 3 & 3.0 & 43.9 \\
\hline 13. Burns & 13 & 1.9 & 43.8 & 13. Sores (granos) & 3 & 3.0 & 46.9 \\
\hline 14. Sores (granos) & 12 & 1.8 & 45.6 & 14. Upset stomach & 3 & 3.0 & 49.9 \\
\hline 15. Colds & 11 & 1.6 & 47.2 & 15. Asthma & 2 & 2.0 & 51.9 \\
\hline 16. Diabetes & 11 & 1.6 & 48.8 & 16. Bleeding & 2 & 2.0 & 53.9 \\
\hline 17. Bladder infection & 10 & 1.5 & 50.3 & 17. Body aches & 2 & 2.0 & 55.9 \\
\hline 18. Constipation & 10 & 1.5 & 51.8 & 18. Boils (tacotes) & 2 & 2.0 & 57.9 \\
\hline 19. Headaches & 10 & 1.5 & 53.3 & 19. Heart problems & 2 & 2.0 & 59.9 \\
\hline 20. Bleeding & 9 & 1.3 & 54.6 & 20. High blood pressure & 2 & 2.0 & 61.9 \\
\hline 21. Congestion & 9 & 1.3 & 55.9 & 21. Infected wounds & 2 & 2.0 & 63.9 \\
\hline 22. Kidney infection & 9 & 1.3 & 57.2 & 22. Nervios & 2 & 2.0 & 65.9 \\
\hline 23. Heart problems & 8 & 1.2 & 58.4 & 23. Pneumonia & 2 & 2.0 & 67.9 \\
\hline 24. Sore throats & 7 & 1.1 & 59.5 & 24. Sore throats & 1 & 2.0 & 69.9 \\
\hline 25. Stomach cramps & 7 & 1.1 & 60.6 & 25. Stomach cramps & 2 & 1.0 & 71.9 \\
\hline \multicolumn{4}{|c|}{ Total $=678$} & \multicolumn{4}{|c|}{ Total $=101$} \\
\hline
\end{tabular}


variables play a part in differentially shaping the morbidity patterns of home treated ailments in ways that are probably similar to those reported by Cole [17] and others for national and regional morbidity studies. Similarly, the differences between the two age ranks for informants of the same sex were significant. for females, the probability that the differences within the two lists of the top ten ailments for the 17-44 group and the $45+$ group were due to chance alone were less than one in a thousand $\left(\chi^{2}=95.5,12 \mathrm{df}\right.$, $P<0.001$ ), and the probability that the differences in the top 10 ailments in each of the two male lists were also less than one in a thousand $\left(\chi^{2}=44.16,15 \mathrm{df}\right.$, $P<0.001$ ). These findings are consistent with other types of morbidity studies, which have shown that such differentials are due, at least in part, to the changing social environment for the individual at various ages and, in part, to the changing physiological characteristics of individuals of varying ages. Thus, all three comparisons produce results that are comparable with conventional morbidity studies.

\section{SUMMARY AND CONCLUSIONS}

The data presented within this paper indicate that an analysis of appropriate samples of remedios caseros can provide a considerable amount of insight into the common ailments treated in the home with ethnopharmacological resources. Further, the morbidity patterns discovered by the analysis of this type of data parallel those from more conventional mortality research efforts, especially in that the patterns of the health problems collected from informants vary significantly in relation to the age and sex of the individual providing the information.

The ailments and groupings of ailments described in this paper are interesting not only for the patterns within the ailments that are included in the sample, but also for the patterns of ailments and groups that are not found in the sample. Since the majority of Mexican Americans in the Valley now have access to medical treatment, it can be assumed that remedios caseros are currently being utilized within the context of a total field of health resources that necessitate someone choosing between home treatment and medical treatment. Some ailments appear to be treated only in the home and others treated only by the medical establishment. Thus, the core ailment group was inspected for regularities that might suggest a rationale behind the choices that are made. The result is that the core ailments were subdivided into three groups: ailments having no medical treatment (e.g. susto, mal de ojo, etc.); ailments that do not normally require medical treatment (e.g. cuts, minor rashes, burns, stomachaches, diarrhea); and ailments that the patient perceives the medical system has failed to cure or eliminate (e.g. terminal cancer, diabetes, balding, or arthritis). The rationale for choosing folk remedies, then, may be a process of evaluating the symptoms an ailment presents, classifying it as a particular ailment, and pursuing treatment. If it is further assessed or categorized as being outside the scope of medical treatment, or if medical treatment has "failed", then, obviously, many people will opt for self help forms of treatment, rather than giving up hope. Naturally, some health problems are extremely ambiguous in their presenting symptoms, and patients will decide to use both systems either simultaneously or sequentially, as discussed in Trotter and Chavira [10].

Future research, both in Mexican American communities and within other cultural groups, which follows or extends the format set out in this paper should produce valuable results in at least two areas. One is a delineation of the parameters of the system of choice that is operating; the factors which determine the course of treatment of an ailment pursued by a patient, both at given points in time and through a course of treatment. The second is in determining the nature and scope of the whole field of home health care and self help patterns, since these are not normally known nor are they commonly capable of being established by other methodologies, yeat they appear to have a major impact on the health status of communities or regions where they are found.

\section{REFERENCES}

1. Tomlinson R. Population Dynamics, 2nd edn. Random House, New York, 1976.

2. National Center for Health Statistics, Health Resources Administration. Health Survey Procedure: Concepts, Questionnaire Development and Definitions in the Health Interview Survey. Public Health Service Publications No. 1000, Series 1, No. 2. U.S. Government Printing Office, Washington, 1964.

3. Patrick D. L., Bush J. W. and Chan Milton M. Toward an operational definition of health. J. Hlth Soc. Behav. 14. 6, 1973.

4. Elinson J. Toward sociomedical health indicators. Soc. Indicat. Res. 1, 59, 1974.

5. Peterson W. Population, 3rd edn. Macmillan, New York, 1975.

6. Berg Robert L. (Ed.) Health Status Indeves. Hospital Research and Education Trust, Chicago, 1973.

7. Elinson J. (Ed.) Sociomedical health indicators. Int. J. Hlth Serv. 6, entire issue, 1976.

8. Pollard William E., Bobbitt Ruth A., Bergner Marilyn, Martin Diane P. and Gilson Betty S. The sickness impact profile: reliability of a health status measure. $M e d$. Cure 14, 146, 1976.

9. Mechanic D. Medical Sociology, 2nd edn. Free Press, New York, 1978.

10. Trotter Robert T. II and Chavira Juan A. Curanderismo: The Gift of Healing. The University of Georgia Press, Athens, Georgia, in press.

11. Clark M. Health in the Mexican American Culture. University of California Press, Berkeley, 1959.

12. Kiev A. Curanderismo: Mexican American Folk Psychiatry. Free Press, New York, 1968.

13. Madsen W. The Mexican Americans of South Texas. Holt, Rinehart, Winston, New York, 1964.

14. Rubel Arthur J. Concepts of disease in a Mexican American community in South Texas. Am. Anthrop. 82. 795, 1960.

15. Rubel Arthur J. The epidemiology of a folk illness: susto in Hispanic America. Ethnology 3, 268, 1964.

16. Kay $M$. Health and illness in a Mexican American barrio. In Ethnic Medicine in the Southwest (Edited by Spicer Edward H.). University of Arizona Press, 1977.

17. Cole P. Morbidity in the United States. In Patients. Physicians, and Illness (Edited by Jaco E. Gartly), pp. 30-52, 3rd edn. Free Press, New York, 1979.

18. STHSA (South Texas Health Systems Agency). Health Systems Plan 1979-1984. South Texas Health Systems Agency, Inc., Kingsville, Texas, 1979.

19. Tomlinson R. Population Dynamics, 2nd edn. Random House, New York, 1976. 